\title{
PERICOL NOU PENTRU POMICULTORI - ERINOZA RUGINIE EUROPEANĂ ACULOPS BEROCHENSIS KEIFER
}

\author{
Iordosopol Elena \\ Institutul de Genetică, Fiziologie și Protecţie a Plantelor, Chișinău, Republica \\ Moldova, iordosopol@yahoo.com \\ https://doi.org/10.53937/9789975315975.44
}

Abstract. The article communicates about the first record in the conditions of 20162018 in the Republic of Moldova on the young plum culture of the species of European rust erinosis Aculops berochensis Keif in the Stenlley and Cacanska rana varieties. Several ways of the pest attacking plum development stages have been observed. It was determined that the highest degree of attack was manifested on the Stenlley variety at the young shoots, and at Cacanska rana leaves. There are 7 species of beneficial insects that regulate numerical density.

Cuvinte cheie: prun, faze de dezvoltare, grad de atac, erinoza, pradatori.

\section{INTRODUCERE}

Cercetările anterioare au evidenţiat la prun un complex constat din 7 specii de acarieni eriofiizi: erinoza galicolă a prunului (Eriophys phloiecoptes), erinoza mare a frunzelor (Rhinophytoptus dudichi Farkas.), erinoza mindalului (E. armeniacus Bagd.), erinoza marginală a frunzelor ( $E$. similis Nal.), erinoza galicolă a frunzelor (E. padi prunianus Nal.), erinoza frunzelor de prun (Aculus fockei Nal.), erinoza mare (Diptacus gigantorhychus Nal.) [1]. Specia de erinoză Aculops berochensis a fost descrisă pentru prima dată de Keifer, Delley în 1971 de pe Prunus domestica [1]. În Federaţia Rusă a fost notată de Zeinalov [3]. În procesul analizei stării fitosanitare a plantaţiei industriale de prun s-a observat moduri de atac nu specifice afidelor și ca scop a fost determinarea dăunătorului care provoacă atacul și a elementelor bioecologice.

\section{MATERIALE ȘI METODE}

În procesul investigării s-au extras mostre de scoarţă, muguri, frunze, inflorescenţe și lăstari. Materialul obţinut s-a analizat prin utilizarea binocularului BEL photonix și binocular/trinocular BIO2. Investigările au 
demarat la SRL. Agrobrio la soiurile Cacanska rana, Stenlley în anul II de rod și la prunul în anul II de după plantare, soiurile Black Betty, Stenlley, la IGFPP.

\section{REZULTATE ȘI DISCUȚII}

Activitatea vitală a erinozei ruginii europene începe încă din faza umplerii mugurilor odată cu celelalte 2 specii de erinoze migrante. Această specie poate fi confundată cu erinoza ruginie a prunului Aculus fockei Nal., care după dimensiuni o depășește. În cazul nostru atacul frunzelor în formă de corăbioare și a lăstarilor, a constatat prezenţa erinozei ruginii europene (foto 1). La suprapopularea lastarului tinăr pot fi observaţi nu numai pe fruzuliţe, dar și pe peţioluri și rămurele (foto 2). Modul de atac al speciei în primele faze de dezvoltare a prunului poate fi confundat cu atacul tripsului Franklinella occidentalis (foto 3), iar în faza de fructificare cu atacul larvelor de afide Myzus persicae, pînă la formarea coloniilor pe frunză.
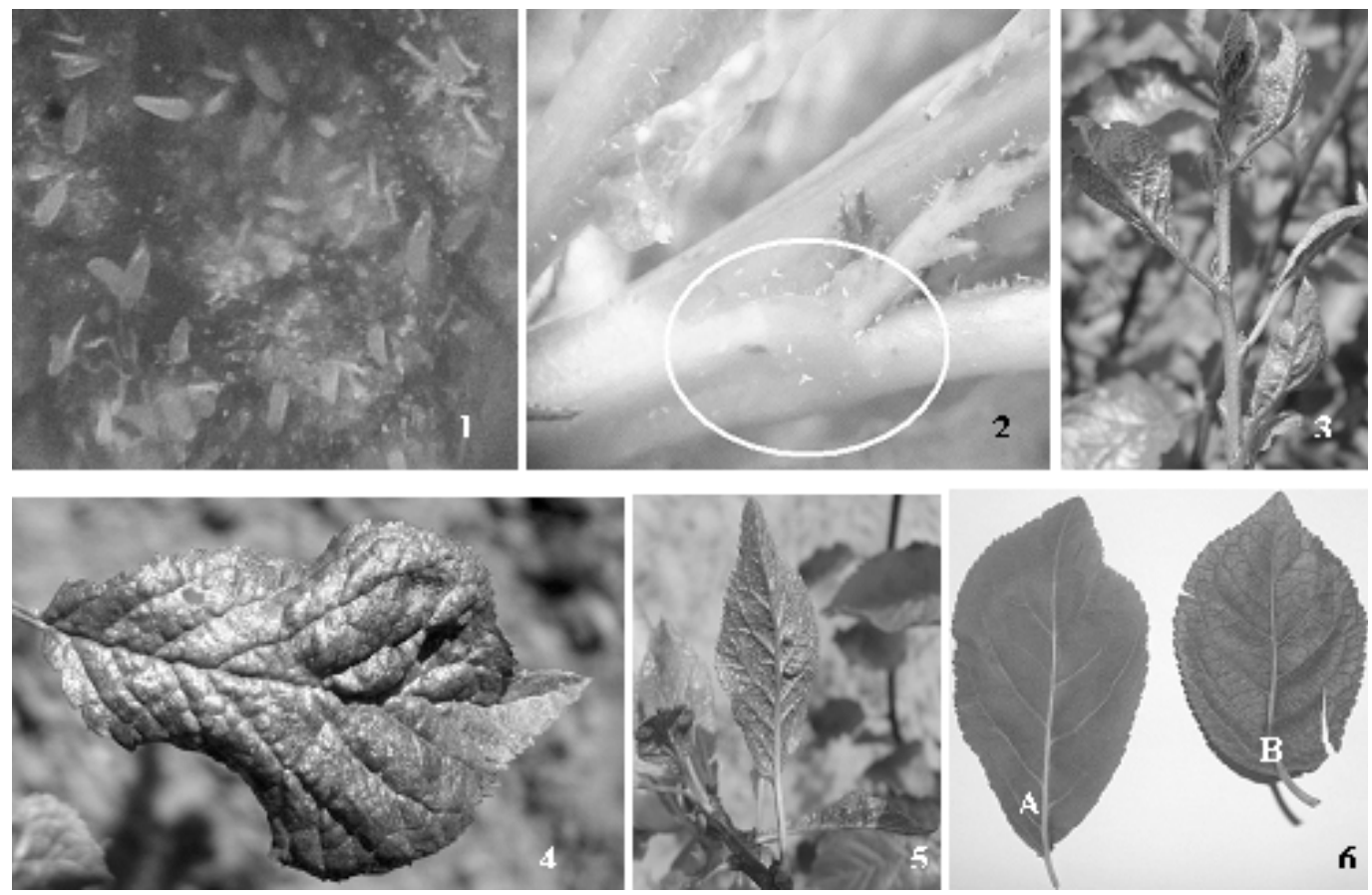

Foto (original). 1 - colonii enorme de Aculops berochenzis Keif. pe frunze; 2 - pe ramuri tinere; 3 - mod de atac pe lăstar tînăr; 4 - pe frunză matură; 5 - pe frunză tînără; 6 - diferenţa comparativă de atac pe frunze (A - frunza sănătoasă, B - frunza atacată) 
Pe măsura maturării aparatului foliar apar noi simptome așa ca: culoarea gălbuie în zona nervurii principale și secundare a limbului pe partea superioară (4); ingroșarea frunzei și obţinerea unul luciu metallic-suriu-uleios pe partea inferioară (5). Pomii atacaţi ușor pot fi observaţi după diferenţa atacului pe Frunze (6). În coloniile dăunătorului pe întreaga perioadă de vegetaţie s-a notat specii prădătoare: ploșniţa Orius sp., tripsul Scolothrips longicornis, acarianul ereinetid Eryneus sp., acarienii fitoseizi Kampimodromus aberrans, Typhlodromus pyri, Paraseiulus subsoleiger și stigmaidul Zetzelia mali.

\section{CONCLUZII}

Pentru prima dată în Republica Moldova s-a notat prezenţa în plantaţiile industriale de prun erinoza ruginie europeană $A$. berochensis Keif. cu un grad înalt de atac în anii 2016-2018. S-au observat 7 specii de prădători-limitatori ai densităţii numerice a daunătorului.

\section{BIBLIOGRAFIE.}

1. Iordosopol E. Acarienii dăunători la cultura prunului și fauna utilă. / Simpoz. Știin. Intern. „Agricultura modernă - realizări și perspective”, Chișinău, 21-23 octombrie 2008,

2. Keifer H. H. Delley B. Description of new of Aculops Keifer (Arachn.., Acar.) noxious on Plumtrees in Swityerland / Bulletin de la Societe Entomologique Susisse, band 44, heft 3-4, 1971, pag. 342-344.

3. Зейналов Ф. С. Эриофиидные клещи увеличивают агрессию на п^одовых культурах. Защита и Карантин, № 6, 2013 г. 